\title{
FORMAÇÃO CONTINUADA DE PROFESSORES: A EDUCAÇÃO DE JOVENS E ADULTOS PARA A JUVENTUDE EM FOCO
}

\section{CONTINUED TEACHER TRAINING: YOUTH AND ADULT EDUCATION FOR YOUTH IN FOCUS}

\section{RESUMO}

Este artigo tem o objetivo descrever e analisar o percurso de organização e execução do curso de Pósgraduação Lato sensu em Educação de Jovens e Adultos para a Juventude na modalidade a distância. A sua oferta ocorreu no período de agosto de 2014 a maio de 2016, pelo Departamento de Química do Instituto de Ciências Exatas e da Terra, da Universidade Federal de Mato Grosso (UFMT), nos polos da Universidade Aberta do Brasil (UAB) de Colíder, Juara, Nova Xavantina e Pontes e Lacerda. O desenvolvimento dos trabalhos proporcionou formação continuada para sessenta e seis professores que atuam na EJA, em vinte e dois municípios do Estado de Mato Grosso. Entendemos que a formação contribuiu para que os educadores, que atuam nessa modalidade de ensino, compreendam a conceituação da palavra juventude e sua situação sociológica na contextualização da escolarização e do mundo do trabalho. Sobretudo, contribuiu para umareflexão sobre suas práticas como intervenções nas escolas de sua comunidade com possibilidade de alterá-las de modo qualitativo.

Palavras chave: Formação Continuada, Educação de Jovens e Adultos, Juventude.

\begin{abstract}
This article aims to describe and analyze the organization and execution of the path course sensu Postgraduate Lato in Youth and Adult Education for Youth in the distance. His offering was from August 2014 to May 2016, the Department of Chemistry Institute of Exact Sciences and Earth, the Federal University of Mato Grosso (UFMT), the poles of the Open University of Brazil (UAB) of Colíder, Juara, New Xavantina and Pontes e Lacerda. The work provided continuing education for sixty-six teachers who work in adult education, in twenty-two counties of the State of Mato Grosso. We understand that the training contributed to the educators who work in this type of education, understand the concept of youth word and its sociological situation in the context of education and the world of work. Above all, it contributed to a reflection on their practices as interventions in their community schools with the possibility to change them qualitatively.
\end{abstract}

Keywords: Continuing Education, Youth and Adult Education, Youth.

\footnotetext{
${ }^{30}$ Doutorando em Educação em Ciências e Matemática pela PPGECEM/REAMEC. Docente do Departamento de Química da Universidade Federal de Mato Grosso (UFMT). marcelufmt @ yahoo.com.br

${ }^{31}$ Doutora em Educação pela USP. Docente do Departamento de Química da Universidade Federal de Mato Grosso (UFMT). icmello@terra.com.br

${ }^{32}$ Doutora em Educação em Ciências e Matemática da Rede Amazônica - PPGECEM/REAMEC. Docente do Departamento de Química da Universidade Federal de Mato Grosso (UFMT). mariuce@ufmt.br

${ }_{33}$ Doutora em Educação pela PUC/RS. Docente do Programa de Pós-Graduação em Ensino de Ciências Naturais - PPGECN/UFMT. Docente do Departamento de Química da Universidade Federal de Mato Grosso (UFMT). elaneufmt@gmail.com
}

Revista REAMEC, Cuiabá - MT, n.05, Volume 1, dezembro 2016, ISSN: 2318 - 6674

Revista do Programa de Doutorado da Rede Amazônica de Educação em Ciências e Matemática

http://revistareamec.wix.com/revistareamec 


\section{REVISTA REAMEC}

\section{Revista da Rede Amazônica de Educação \\ em Ciências e Matemática}

\section{INTRODUÇÃO}

A temática central deste artigo é o entrelaçamento entre os desafios da educação da juventude na contemporaneidade e uma pertinente formação continuada de professores para a educação básica. Para tanto, adentramos na questão da Educação de Jovens e Adultos para a Juventude. No dicionário Aurélio Buarque de Holanda lê-se que adolescente é a pessoa que 121 está na adolescência, isto é, no período da vida humana que começa com a puberdade e se caracteriza por mudanças corporais e psicológicas, estendendo-se, aproximadamente, dos 12 aos 20 anos. Para a palavra jovem, o mesmo dicionário dá como sinônimo moço. O mesmo vale para juventude idade moça, mocidade, juvenil. Dá para concluir, segundo o dicionário supracitado, que nem a juventude nem o jovem correspondem a uma categoria social. Apesar de se falar de jovem e de juventude, eles não existem como realidade específica.

A opinião de Abramo sobre a temática juventude nos revela que:

A noção mais geral e usual do termo juventude se refere a uma faixa de idade, um período de vida, em que se completa o desenvolvimento físico do indivíduo e ocorre uma série de transformações psicológicas e sociais, quando este abandona a infância para processar sua entrada no mundo adulto. No entanto, a noção de juventude é socialmente variável. A definição do tempo de duração, dos conteúdos e significados sociais desses processos se modifica de sociedade para sociedade e, na mesma sociedade, ao longo do tempo e através de suas divisões internas. Além disso, é somente em algumas formações sociais que a juventude configura-se como um período destacado, ou seja, aparece como uma categoria com visibilidade social (Abramo, 1994, p. 01).

Tendo em vista, as mutações que atingem a esfera do trabalho e da escola, é cada vez mais necessário um olhar aprofundado para os percursos dos jovens nessas esferas, principalmente no Brasil, pois aqui, para além da escola, o trabalho também faz a juventude. Tal como afirma Spósito: “[...] para os jovens brasileiros, escola e trabalho são projetos que se superpõem ou poderão sofrer ênfases diversas de acordo com o momento do ciclo de vida e as condições sociais que lhes permitam viver a condição juvenil” (2005, p.106). Ainda, segundo a mesma autora, reconhecer que no Brasil o trabalho também faz a juventude não significa, de maneira ingênua, defender o trabalho de adolescentes e jovens, mas, ao contrário:

Implica admitir que, se a construção da condição juvenil decorre de um complexo de valores sedimentados sob o ponto de vista social e histórico, no Brasil, uma alteração desse quadro deveria ser expressão de mudanças estruturais mais substantivas que atenuem as profundas desigualdades sociais, submetidas a processos de longa duração (2005, p.226).

Morgado e Sanches contribuem ao afirmar que 


\section{REVISTA REAMEC}

Revista da Rede Amazônica de Educação

em Ciências e Matemática

A população juvenil brasileira tem como maior preocupação a escolarização e o trabalho. Porém, na região Centro-Oeste verifica-se que entre aqueles que não estudam e não trabalham ocorre considerável diminuição, sinalizando que os jovens estão focalizados no seu futuro, que passa pela escolarização e ocupação (2007, p.36).

É preciso priorizar o jovem no contexto precarizado e excludente que a ele se apresenta neste início de século XXI. Faz-se necessária a criação de políticas públicas que Página | proporcionem aos segmentos mais vulneráveis, oportunidade de vida melhor e aos segmentos médios, oportunidades de inserção no trabalho.

Em geral, no Brasil, o jovem pobre se insere precocemente no mundo do trabalho, com frequência antes de terminar o ensino fundamental. Também, de modo geral, os jovens de classe média ingressam no mundo do trabalho após passarem pelo sistema de ensino fundamental, médio e superior. Isso indica que a escolarização está ligada ao trabalho, principalmente na colocação no primeiro emprego (MORGADO E SANCHES, 2007).

Essa população jovem também necessita de mediações para a transição, desde sua inatividade até sua atividade produtiva, de maneira protegida. Sobretudo, para os jovens das camadas populares, a ampliação do tempo de preparação no processo educacional não assegura ingresso no mundo do trabalho qualificado, em condições de igualdade, em relação a outros jovens de camadas mais abastadas. Como se sabe, o jovem com maior disponibilidade financeira geralmente tende a permanecer maior tempo na escola e, consequentemente, adia seu ingresso no mundo do trabalho. Com isso, adquirem condições de escalar os melhores postos de trabalho, ao contrário daqueles que tiveram de trocar a escola pelo ingresso prematuro no mundo do trabalho.

Diante do exposto, compreendemos ser relevante entender a Juventude na contemporaneidade e no contexto da Educação de Jovens Adultos como uma exigência para a docência de educadores que atuam nessa modalidade de ensino, bem como refletir sobre os entrelaçamentos entre os desafios desta educação e uma pertinente formação continuada de professores. Para tanto, adentramos na questão da Educação de Jovens e Adultos para a Juventude, de modo que o objetivo deste artigo é descrever e analisar o percurso de uma formação a distância, em nível de pós-graduação, para professores da educação básica de Mato Grosso, comprometida com os desafios da educação da Juventude em nossa época.

\section{PERCURSO METODOLÓGICO}




\section{REVISTA REAMEC}

\section{Revista da Rede Amazônica de Educação \\ em Ciências e Matemática}

Este artigo configura-se como uma investigação desenvolvida no âmbito da pesquisa educacional qualitativa, que recorre ao relato de experiência como estratégia metodológica, nos termos que nos apresenta Pádua (2014). Segundo a autora, essa estratégia de pesquisa, por seu caráter multidimensional, apresenta-se como possibilidade de compreender a ação humana, histórica e socialmente contextualizada e, ao mesmo tempo propicia revitalização das teorias inerentes ao tema em estudo. Assim, ela nos oferece condições de construção de conhecimento quer seja no plano individual quer seja no plano grupal ou social. No âmbito deste trabalho, essa orientação é destinada à reflexão sobre o entrelaçamento de múltiplas ações, na busca por uma totalidade formativa. Deste modo, tomamos por procedimentos a recuperação e significação de processos, atividades e comunicações marcantes em experiências vividas, desde o ano de 2014 até 2016, na formação continuada de professores da Educação Básica.

A interpretação das experiências relatadas desenvolveu-se colocando em articulação um estudo de natureza descritiva e uma análise construtivo-interpretativa do conhecimento (GONZÁLEZ-Rey, 2005). Sendo assim, o cenário de pesquisa corresponde a espaços formativos gerados junto ao curso de Educação de Jovens e Adultos/EJA para a Juventude, oferecido em nível de pós-graduação Lato Sensu, nos polos da Universidade Aberta do Brasil (UAB) de Mato Grosso.

Nesse sentido, o curso se justificou, para que os educadores que atuam nessa modalidade de ensino compreendessem melhor esse sujeito jovem que a cada dia se apresenta como protagonista dessa modalidade de ensino e, para que pudessem desenvolver a capacidade de selecionar conteúdos, utilizar procedimentos e criar alternativas que possibilitem uma atuação voltada de forma mais adequada ao estudante jovem trabalhador.

\section{EDUCAÇÃO DE JOVENS E ADULTOS PARA A JUVENTUdE: O COMPROMISSO CONTEMPORÂNEO}

Os conceitos de adolescência e juventude correspondem a uma construção social, histórica, cultural e relacional, que, por diferentes épocas e processos históricos e sociais, foram adquirindo denotações e delimitações diferentes. $\mathrm{O}$ pequeno intervalo entre ambos os estágios é o que se costuma conceber como campo de estudo e conceituação da juventude e da 


\section{REVISTA REAMEC}

\section{Revista da Rede Amazônica de Educação \\ em Ciências e Matemática}

adolescência, com delimitações não completamente claras em ambas, que em muitos aspectos se sobrepõem, dependendo dos enfoques utilizados para estes efeitos.

A responsabilidade analítica do termo e do tema adolescência tem sido atribuída à psicologia, na perspectiva de uma análise e delimitação partindo do sujeito em particular e seus processos e transformações como indivíduo, deixando a outras disciplinas, como as das áreas de ciências humanas e sociais, a discussão da categoria juventude em especial à sociologia, antropologia cultural e social, história, educação, estudos culturais, comunicação, entre outras.

Nessa perspectiva, Dick corrobora que:

- Adolescência e juventude não são sinônimas. São duas realidades diferentes.

- As definições de juventude passeiam entre dois critérios principais, que nunca se conciliam realmente; o critério etário e o critério sociocultural.

- O pressuposto fundamental da discussão é que a idade é um fenômeno social e não apenas biológico. O que existe em cada período histórico é um conjunto multifacetado de jovens, condicionados e interagindo com o meio social em que vivem.

- O termo juventude é polissêmico, revestindo uma série de significados, mas três adjetivações principais estão associadas a eles; (1) um período etário, situado entre a infância e a idade adulta; (2) certo estado de espírito; e (3) um estilo de vida.

- Podemos definir a juventude como uma categoria social. Essa "categoria" faz a juventude mais do que uma faixa etária e não faz da juventude um grupo coeso ou uma classe de fato. A juventude torna-se, uma representação sociocultural (a juventude é uma concepção, representação ou criação simbólica, fabricada pelos grupos sociais ou pelos próprios indivíduos tidos como jovens, para significar uma série de comportamentos e atitudes a eles atribuídos); e uma situação social (a juventude é uma situação vivida em comum por certos indivíduos).

- A categoria social juventude tem uma importância crucial para o entendimento de diversas características das sociedades modernas, o funcionamento delas e suas transformações (2003, p.26-27).

Uma reflexão que parece fundamental nesse debate sobre juventude, juventudes ou juventude e adolescência é a questão da moratória vital (DICK, 2003). Nesses termos,

[...] trata-se de pensar a juventude como um período da vida em que alguém está de posse de um excedente temporal e de um crédito, como se tratasse de algo que se teria poupado, de algo que se tem a mais e do qual se pode dispor, de algo que, nos não jovens, se vai gastando e vai terminando, irreversivelmente, por mais esforços que se faça para evitá-lo (DICK, 2003, p.27). 


\section{REVISTA REAMEC}

\section{Revista da Rede Amazônica de Educação \\ em Ciências e Matemática}

Ser jovem é ter um capital temporal, carregando consigo, de forma muito particular, a esperança, a promessa e um espectro de opções. É o que se chama de moratória vital, um fato inegável. Por essa perspectiva, além de tudo, tem sentido a valorização etária. Atrás do conceito idade, mora uma realidade que é comum a todos os que têm determinada idade. Dick (2003) esclarece que a moratória vital pode ser agredida, pode não ser considerada, pode ser diminuída, mas ela é real, e que, graças a essa realidade é que se pode distinguir (sem confundir) os jovens e os não jovens. Por meio da moratória social, podemos distinguir somente o juvenil e o não juvenil, não os jovens e os não jovens.

Assim como pode haver jovens juvenis, pode haver não jovens juvenis. Com a noção de moratória vital (capital ou potencial energético) como característica de juventude, podemos falar de algo que não muda por classe, porque esse algo depende de um outro segmento, isto é, de suas forças disponíveis, de sua capacidade produtiva, de suas possibilidades de deslocamento, de sua resistência ao esforço, entre outros. Dessa forma, Dick (2003) conclui que a juventude, como plus de energia (moratória vital e não somente social) ou como crédito temporal, é algo que depende da idade, sendo um fato evidente sob todos os pontos de vista.

\section{FORMAÇÃO CONTINUADA A DISTANCIA: O CURSO PROPOSTO}

O Departamento de Química do Instituto de Ciências Exatas e da Terra, da Universidade Federal de Mato Grosso (UFMT) ofertou, pela primeira vez no Estado de Mato Grosso, na modalidade a distância, o curso de Pós-Graduação Lato Sensu em Educação de Jovens e Adultos para a Juventude. O curso foi autorizado pelo Parecer Técnico nº 33/2014 DPEJUV/SECADI/MEC, pela Resolução CONSEPE n 90/2014 e pela Portaria ICET n $^{\circ}$ 17/2014, para um público de 25 estudantes em quatro polos da Universidade Aberta do Brasil (UAB), no interior do Estado (Colíder, Juara, Nova Xavantina e Pontes e Lacerda), totalizando 100 vagas.

A oferta dessa especialização se deu em virtude da experiência de pesquisadores do Laboratório de Pesquisa e Ensino de Química (LabPEQ) do Departamento de Química da UFMT, com a temática da Juventude e Educação de Jovens e Adultos na Educação Básica no Estado de Mato Grosso e em resposta à chamada pública para manifestação de interesse quanto à proposição de cursos de formação continuada para professores da Educação Básica, mediante adesão ao catálogo MEC/SECADI 2014, mediante Comitê Gestor Institucional- 


\section{REVISTA REAMEC}

Revista da Rede Amazônica de Educação

em Ciências e Matemática

UFMT (COMFOR-UFMT) e da Rede Nacional de Formação Inicial e Continuada de Profissionais do Magistério da Educação Básica (RENAFORM).

\subsection{OBJETIVOS DO CURSO}

O curso foi proposto apoiando-se em múltiplos objetivos dos quais destacamos:

articular o debate acerca da especificidade da Educação de Jovens e Adultos e a Juventude, bem como da sua relação com o mundo do trabalho; ampliar fundamentos teóricos que embasem o processo ensino-aprendizagem de jovens e adultos; possibilitar a apropriação de abordagens e metodologias interdisciplinares direcionadas para uma maior eficiência das práticas educativas na EJA; propiciar o desenvolvimento de conhecimentos, habilidades, atitudes e valores pertinentes à atividade docente; discutir as políticas públicas existentes nas áreas de Educação de Jovens e Adultos e Juventude, no sentido de estimular a construção conjunta de propostas que visem à melhoria da qualidade de vida das pessoas envolvidas nesses processos; possibilitar conhecimentos e estimular a produção de pesquisa e de reflexões que potencializem a interface entre Educação de Jovens e Adultos e a Juventude.

\subsection{O PÚBLICO-ALVO}

O curso se destinou a professores, técnicos administrativos e técnicos em assuntos educacionais, da rede pública (estadual, municipal) do Estado de Mato Grosso, e os critérios de seleção dos candidatos se deram da seguinte forma: atuação profissional na área de Educação de Jovens e Adultos; possuir formação superior em curso aprovado ou reconhecido pelo MEC; análise dos motivos pelos quais o candidato estava interessado em fazer o curso.

A seleção dos candidatos ocorreu nos meses de agosto e setembro de 2014 e ingressaram, inicialmente, 25 estudantes entre professores, técnicos administrativos e técnicos em assuntos educacionais, que atuavam na educação básica na modalidade de Educação de Jovens e Adultos, em cada polo da UAB/UFMT de Colíder, Juara, Nova Xavantina e Pontes e Lacerda, totalizando 100 estudantes.

\section{METODOLOGIA DO CURSO}

A metodologia do curso buscou desenvolver-se mediante uma interação dialógica entre saberes, teoria e práticas e entre os envolvidos no processo do curso de especialização. 


\section{REVISTA REAMEC}

Revista da Rede Amazônica de Educação

em Ciências e Matemática

O desenvolvimento a distância se processou a partir da interatividade do tutor com os cursistas, via internet, na plataforma Moodle. O curso teve como referência para o seu desenvolvimento, o portal da UAB, na página virtual da UFMT (http://www.uab.ufmt.br/). Os tutores acompanharam os cursistas que puderam formar grupos de estudo, a fim de facilitar a compreensão das temáticas e a elaboração de novos textos, de maneira virtual.

\subsection{DA ORGANIZAÇÃO E EXECUÇÃO DO CURSO}

O curso foi organizado em 12 disciplinas cada qual com uma base de dados na qual o cursista postou a atividade correspondente às disciplinas (doze disciplinas/fascículos). Entende-se por fascículo, o material impresso/digital contendo as disciplinas e suas temáticas, além de um guia didático de estudo. Antes do início de cada disciplina, cada estudante recebeu um exemplar do fascículo, em formato digital, correspondente à disciplina que estava cursando. Esses fascículos estão disponíveis em PDF no site do Curso, no endereço (http://www.uab.ufmt.br/).

Em cada disciplina foi aberto, além de espaço para postagem de arquivos/tarefas, um Fórum de discussão para debates, esclarecimentos de dúvidas sobre as leituras feitas, descoberta e afirmações de aprendizagens que ficaram abertas até o final do curso. Neste espaço, o cursista pôde, sempre que julgasse necessário, interagir com o professor formador e com o tutor para tirar dúvidas, solicitando esclarecimentos sobre a temática estudada e também apresentando suas contribuições.

O Curso, além de contar com o trabalho dos tutores, contou também com o trabalho e dedicação da coordenação, dos Professores-pesquisadores autores, responsáveis pelas disciplinas e com o trabalho dos Professores-pesquisadores formadores, que orientaram e acompanharam o processo de ensino-aprendizagem dos estudantes do Curso de Especialização em EJA para a Juventude - EaD.

\subsection{A ESTRUTURA CURRICULAR DO CURSO}

A estrutura curricular foi composta de 12 disciplinas/fascículos, que totalizaram 360 horas, distribuídas em $288 \mathrm{~h}$ a distância, destinadas para os estudos dos fascículos e realizações de atividades; e $72 \mathrm{~h}$ presenciais, destinadas para os encontros presenciais, nos polos da UAB/UFMT, para o auxílio em atividades, orientações dos fascículos e realizações 


\section{Revista da Rede Amazônica de Educação \\ em Ciências e Matemática}

de provas presenciais obrigatórias. As disciplinas/fascículos foram distribuídas de acordo com a Tabela 1:

Tabela 1: Matriz Curricular Pós-Graduação Lato sensu em Educação de Jovens e Adultos para a Juventude

\begin{tabular}{l|c}
\hline DISCIPLINAS & CH \\
\hline Tecnologia da Informação para a Educação a Distância & 20 \\
\hline $\begin{array}{l}\text { Panorama histórico de EJA no Brasil e Mato Grosso e Fundamentos, } \\
\text { Concepções e Princípios da EJA }\end{array}$ & 30 \\
\hline A Juventude no Contexto da Educação de Jovens e Adultos & 30 \\
\hline $\begin{array}{l}\text { Metodologia do Ensino da Língua: Gramática e Produção de Texto para } \\
\text { Educação de Jovens na EJA }\end{array}$ & 30 \\
\hline A Educação de Jovens e Adultos e o Mundo do Trabalho & 30 \\
\hline $\begin{array}{l}\text { A arte e a ciência de orientar Jovens - Andragogia e Paulo Freire no } \\
\text { contexto da EJA }\end{array}$ & 30 \\
\hline $\begin{array}{l}\text { Metodologia do Ensino das Ciências Humanas e Sociais para Educação de } \\
\text { Jovens na EJA }\end{array}$ & 30 \\
\hline $\begin{array}{l}\text { Fundamentos e Práticas de Pesquisa Científica para a Educação de Jovens } \\
\text { na EJA }\end{array}$ & 30 \\
\hline Políticas de Currículo no Contexto da EJA & 30 \\
\hline $\begin{array}{l}\text { Metodologia do Ensino das Ciências da Natureza para Educação de } \\
\text { Jovens na EJA }\end{array}$ & 30 \\
\hline \begin{tabular}{l} 
Metodologia do Ensino da Matemática para Educação de Jovens na EJA \\
\hline Planejamento de Ensino e Avaliação na EJA
\end{tabular} & 30 \\
\hline
\end{tabular}

Fonte: Elaboração dos autores (2016)

Para a integralização curricular do curso de Especialização em EJA para a Juventude, o professor/cursista precisou cumprir a carga horária referente aos créditos de cada disciplina e ser aprovado, segundo os critérios de avaliação da UFMT, em cada disciplina. Adicionalmente, para a conclusão do curso foi necessário a elaboração de um trabalho de conclusão de curso - TCC com a temática da Juventude no contexto da Educação de Jovens e Adultos, nos municípios onde esses professores/cursistas atuavam.

\section{AVANÇOS E DESAFIOS NA FORMAÇÃO CONTINUADA COMPROMETIDA COM A EJA PARA A JUVENTUDE}

Segundo estudos realizados por Di Pierro (2000), no final da década de 1990, a população que procurava a EJA passou a ser formada por pessoas mais jovens, e não apenas 


\section{REVISTA REAMEC}

\section{Revista da Rede Amazônica de Educação \\ em Ciências e Matemática}

por adultos trabalhadores descolarizados, uma vez que esta modalidade de educação "converteu-se também em mecanismo de aceleração de estudos, para adolescentes e jovens com baixo desempenho na escola regular" (p.64). E, de acordo com Ribeiro (2009), na educação básica no Estado de Mato Grosso, o maior número de sujeitos que frequentam a EJA faz parte da população juvenil.

Neste sentido, o Curso de Especialização aqui apresentado procurou proporcionar formação continuada aos professores que atuam na EJA propiciando condições teóricometodológicas para que esses educadores, na condição de cursistas, fizessem estudos, construíssem projetos de pesquisas, realizassem diagnósticos, problematizassem os elementos concretos de sua realidade, possibilitando oportunidades para reflexão sobre suas práticas, e em como pudessem fazer intervenções nas escolas de sua comunidade com possibilidade de alterá-las no sentido qualitativo.

A proposta da pós-graduação em nível de especialização foi elaborada por meio do trabalho articulado de professores da área de Ensino de Química, do Departamento de Química do Instituto de Ciências Exatas e da Terra da UFMT, de professores do Instituto de Educação da UFMT e contou com a colaboração de professores vinculados à Coordenadoria da Educação de Jovens e Adultos da Secretaria de Educação do Estado de Mato Grosso (SEDUC/MT).

Dos 103 professores/cursistas matriculados inicialmente, concluíram o curso com aproveitamento um total de 66 dos referidos cursistas, sendo 17 do polo de Colíder, 17 do polo de Nova Xavantina, 16 do polo de Juara e 16 do polo de Pontes e Lacerda. Nesse sentido, o curso obteve $64,07 \%$ dos cursistas com aproveitamento no curso, 15,53\% ficaram reprovados por média ou no TCC e $20,38 \%$ evadiram do curso.

Vale destacar que, um dos pontos positivos da oferta do curso de Especialização em Educação de Jovens e Adultos para a Juventude foi a oferta desse curso na modalidade a distância, pois o Estado de Mato Grosso tem extensão territorial continental, com um total de 141 municípios e, levar formação continuada de qualidade e gratuita para professores da educação básica que atuam na EJA, foi um dos pilares e objetivos da coordenação e supervisão do referido curso. 


\section{REVISTA REAMEC}
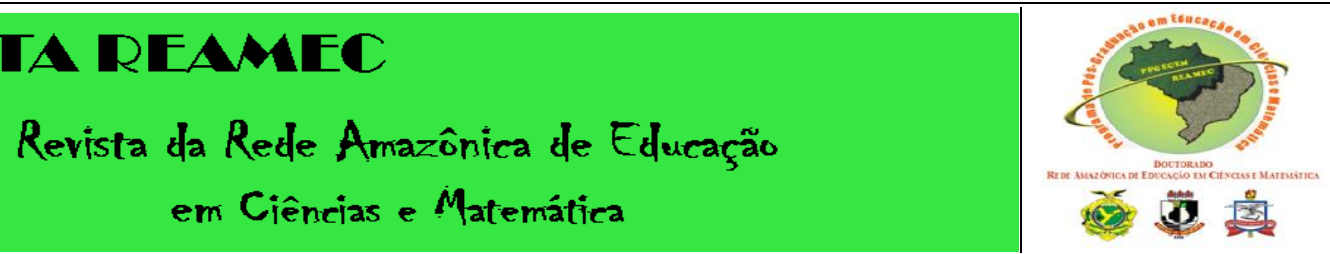

Assim, com essa idealização de formação posta, conseguimos levar a formação continuada para professores da educação básica em 22 municípios do Estado de Mato Grosso, a saber: os estudantes que frequentavam o polo UAB/UFMT de Colíder eram oriundos dos municípios de Alta Floresta, Colíder, Guarantã do Norte, Itaúba, Matupá, Peixoto de Azevedo, União do Sul e Zona Rural de Colíder; os estudantes que frequentavam o polo UAB/UFMT de Juara eram oriundos dos municípios de Itanhangá, Juara, Juruena, Nova Maringá e Novo Horizonte do Norte; os estudantes que frequentavam o polo UAB/UFMT de Nova Xavantina eram oriundos dos municípios de Água Boa, Barra do Garças, Confresa, Nova Xavantina e São Félix do Araguaia; e, por fim, os estudantes que frequentavam o polo da UAB/UFMT de Pontes e Lacerda eram oriundos dos municípios de Cáceres, Mirassol D’Oeste, Nova Lacerda e Pontes e Lacerda.

\section{CONSIDERAÇÕES}

Diante do exposto, finalizamos com a passagem de Gadotti (2002) que afirma que ser professor, hoje, não é nem mais difícil e nem mais fácil do que eram algumas décadas passadas. Ele afirma que é diferente, ou seja, diante da velocidade com que a informação se desloca, envelhece e morre, diante de um mundo que muda constantemente, senão na essencial tarefa de educar, pelo menos na tarefa de ensinar, de conduzir a aprendizagem; a formação docente torna-se permanentemente necessária.

Nesse contexto, o professor é mais um mediador do conhecimento diante do seu educando, que é o sujeito da sua própria formação. O estudante da EJA precisa construir e reconstruir conhecimento a partir do que faz, para isso, o professor também precisa ser curioso, buscar sentido para o que faz e mostrar novos sentidos para o que fazer juntos com os educandos. Assim, ele deixará de ser um simples lecionador, para ser um organizador da aprendizagem. Compartilhando a responsabilidade da aprendizagem do estudante com todos os agentes da escola, ela também está desafiada a mudar a lógica da construção de conhecimento, pois a aprendizagem agora ocupa toda a nossa vida; e porque passamos grande parte do tempo de nossas vidas na escola, devemos e temos que ser felizes nela. A felicidade na escola não é uma questão de opção metodológica ou ideológica, mas uma obrigação essencial dela. E, foi nessa ambiência que se concretizou este curso de formação continuada em Educação de Jovens e Adultos para a Juventude. 


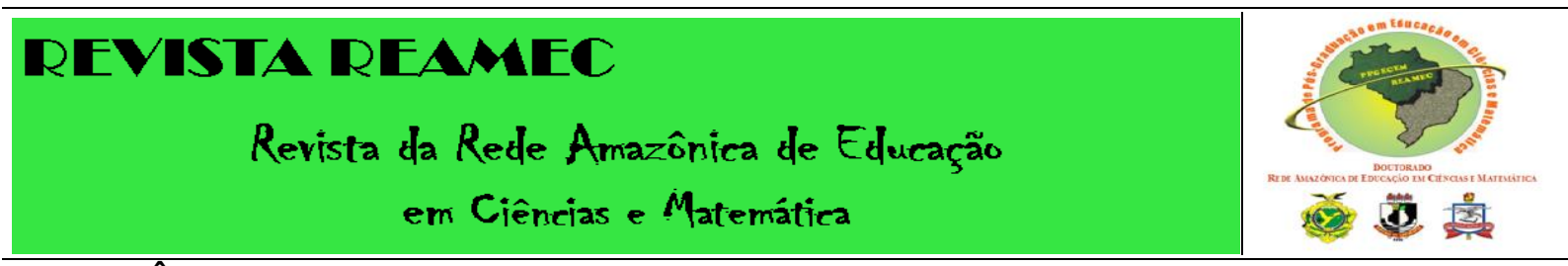

REFERÊNNCIAS

ABRAMO, H. W. Cenas Juvenis: Punks e Darks no espetáculo urbano. São Paulo: Scritta, 1994.

DICK, H. Gritos Silenciados, mas evidentes: Jovens construindo juventude na História. São Paulo: Edições Loyola, 2003.

DI PIERRO, M. C. As políticas públicas de educação básica de jovens e Adultos no Brasil do período 1985/1999. São Paulo: 2000. 314p. Tese Doutorado - PUCSP.

FERREIRA, A. B. de H. Miniaurélio: o dicionário da língua portuguesa.6.ed. Curitiba: Positivo, 2006.

GADOTTI, M. Boniteza de um sonho: ensinar e aprender com sentido. São Paulo: Cortez, 2002. 48p.

GONZÁLEZ-REY, F. L. Pesquisa Qualitativa: os processos de construção da informação. São Paulo: Pioneira Thomson Learning, 2005.

LEVI, G; SCHMITT, J-C. História dos Jovens. 2.v. São Paulo: Companhia das Letras, 1996.

MORGADO, M. A.; SANCHES, M. U. C. Realidades Juvenis em Mato Grosso: Escola, Socialização e Trabalho.Cuiabá: EDUFMT, 2007.

PÁDUA, E. M. M. Pesquisa e complexidade: estratégias metodológicas e multidimensionais. 1 ed. Curitiba:PR: CRV, 2014.

RIBEIRO, M. T. D. Jovens na Educação de Jovens e Adultos e sua Interação com o Ensino de Química. Dissertação (Mestrado em Educação), Faculdade de Educação, Universidade Federal de Mato Grosso. Cuiabá: 2009. 152p.

SPÓSITO, M. P. Algumas reflexões e muitas indagações sobre as relações entre juventude e escola no Brasil.In: ABRAMO, Helena; BRANCO, Pedro Paulo (org). Retratos da Juventude Brasileira. 1.ed. São Paulo: Fundação Perseu Abramo e Instituto de Cidadania, v.1, 2005. 87-128p.

UNIVERSIDADE FEDERAL DE MATO GROSSO. Projeto Pedagógico do Curso de Especialização em Educação de Jovens e Adultos para a Juventude. Cuiabá: UFMT/ICET, 2014. 